A N N A L E S Annales de Bretagne et des Pays de l'Ouest

\title{
Les colonnes infernales
}

\section{Youenn Le Prat}

\section{(2) OpenEdition}

\section{Journals}

Édition électronique

URL : http://journals.openedition.org/abpo/3461

DOI : 10.4000/abpo.3461

ISBN : 978-2-7535-5365-1

ISSN : 2108-6443

\section{Éditeur}

Presses universitaires de Rennes

Édition imprimée

Date de publication : 30 décembre 2016

Pagination : 200-201

ISBN : 978-2-7535-5363-7

ISSN : 0399-0826

\section{Référence électronique}

Youenn Le Prat, «Les colonnes infernales », Annales de Bretagne et des Pays de l'Ouest [En ligne], 123-4

2016, mis en ligne le 30 décembre 2016, consulté le 23 septembre 2020. URL : http://

journals.openedition.org/abpo/3461; DOI : https://doi.org/10.4000/abpo.3461 
Rolland-Boulestreau, Anne, Les colonnes infernales. Violences et guerre civile en Vendée militaire (1794-1795), Paris, Fayard, 2015, 335 p.

On sait que la guerre de Vendée se prolonge en une guerre des mémoires et une historiographie longtemps très clivée. La question des " colonnes infernales " qui opérèrent en Vendée militaire entre le mois de janvier et l'été 1794 participe pleinement de la " machine à fantasmes " révolutionnaire.

Anne Rolland-Boulestreau a rouvert ce dossier en étudiant les rapports conservés au Service Historique de la Défense rédigés par les officiers généraux commandant les colonnes. Cela lui permet de compléter la documentation publiée, entre 1824 et 1827, par l'ancien adjudant-général d'une des colonnes de 1794, JeanJulien Savary, dans sa Guerre des vendéens et des chouans contre la République. Elle fait le choix de ne prendre en compte " aucun écrit postérieur [...] malgré les informations qu'il pourrait apporter sur les actions républicaines [...] ". Un tel corpus comporte donc le risque de ne donner qu'une vision unilatérale de ce conflit lui-même asymétrique. De fait, les combattants comme les habitants de la Vendée militaire ne sont vus ici qu'à travers les rapports adressés au pouvoir politique par des officiers généraux. Les soldats républicains eux-mêmes semblent fondus dans la masse de leur unité. C'est donc bien la vision d'une " généralocratie " menant une guerre contre-insurrectionnelle qui est analysée. L'auteur s'essaie d'ailleurs à une prosopographie des 32 officiers généraux qui se sont succédé à la tête les colonnes. Pour la plupart, ces " généraux ordinaires " étaient déjà dans l'armée avant la Révolution, qui a joué pour eux le rôle d'un " accélérateur de carrière ".

L'auteur nous plonge donc au cœur de la période qui s'étend de janvier jusqu'à l'automne 1794. Si l'on peut regretter que le bilan militaire et politique de l'insurrection vendéenne de 1793 ne soit guère présenté de manière détaillée, Anne RollandBoulestreau renouvelle notre connaissance des colonnes de Turreau - et de ses successeurs - en s'appuyant sur l'historiographie récente de la guerre. Un premier versant de l'ouvrage consiste en l'analyse du "vécu de guerre et ce qui en forme le cœur : l'expérience individuelle de la violence ", pour reprendre les mots de Christian Ingrao. Les combats eux-mêmes sont rarement décrits dans les sources, mais ils ne constituent que des moments paroxystiques. Ce qui frappe, c'est le sentiment de peur, omniprésent chez les soldats républicains. Cette peur obsidionale, c'est " la certitude où est le soldat [...] que, s'il tombe vivant dans les mains des rebelles, il est sûr d'être tué et souvent de la manière la plus cruelle " comme l'écrit Turreau. C'est qu'il ne s'agit pas là d'une guerre réglée entre armées régulières. Ce n'est d'ailleurs qu'en conclusion qu'est abordée la question de savoir comment qualifier ce type de guerre. Génocide ne convient pas, faute d'un plan conscient d'extermination, selon Anne Rolland-Boulestreau, et elle conclut prudemment qu'il ne s'agit pas non plus une guerre totale faute d'une mobilisation complète des ressources par la République. Elle privilégie le concept de guerre civile en insistant sur la crise extrême que traverse l'État. Sans doute, mais les notions de conflit asymétrique ou d'opérations contre-insurrectionnelles auraient pu enrichir l'analyse. Pour désigner les violences commises par les colonnes, elle retient le terme de massacre.

On le sait, la guerre civile, comme le processus de totalisation de la guerre, se caractérisent par une entreprise de déshumanisation. L'auteur, qui porte au lexique employé par les généraux une attention constante, souligne les nombreuses métaphores médicales et cynégétiques qui servent à désigner l'ennemi vendéen. Elles participent d'une déshumanisation de l'ennemi et prennent place dans une montée vers les extrêmes. La Vendée " enragée " risque de contaminer le corps politique républicain, selon les généraux et des mesures prophylactiques s'imposent en conséquence : il convient d'isoler et de purger la Vendée de ses "brigands". Les 
opérations militaires s'apparentent à des chasses aux nuisibles, loups ou renards, et en particulier à des battues.

C'est dans ce contexte qu'est mis en place le système des colonnes, dont l'analyse constitue un autre axe majeur de l'ouvrage. Le général Turreau propose, à la mi-janvier 1794, de faire traverser le pays insurgé par des colonnes avec l'intention " de tout incendier " et de rafler les grains. Le Comité de salut public lui donne son aval le 9 février. Le plan est constamment confronté aux difficultés pratiques. Ainsi, les effectifs des colonnes - douze, réduites en fait à onze - sont mal évalués par les généraux et très fluctuants. Les effectifs de l'armée de l'Ouest dans leur globalité donnent d'ailleurs lieu à des estimations très variables. En outre, les opérations sont compliquées par la méconnaissance du pays, véritable terra incognita en dehors des axes principaux, le long desquels se déploie la violence des colonnes. Les combattants vendéens ont la maitrise du reste de la trame viaire, véritable "labyrinthe " selon le général Ferrand. Les "mauvais chemins ", souvent remplis d'eau et de boue, ralentissent la progression des colonnes qui s'y aventurent. Les insurgés attaquent régulièrement les convois qui empruntent les routes, au risque d'asphyxier bastions et colonnes. Ces dernières sont en outre constamment aux prises avec les difficultés logistiques, du fait de la conjoncture difficile de l'hiver et du printemps 1794, mais aussi de leur mobilité. Une colonne en marche ne peut en effet transporter avec elle toute la nourriture dont elle a besoin. Le soldat républicain manque de pain, de poudre, de souliers et d'uniformes. Les soldats exposés aux éléments et mal nourris sont sujets aux maladies, en particulier à la dysenterie. Les difficultés logistiques renforcent le recours au pillage. Divers trafics s'organisent d'ailleurs au sein de l'armée républicaine en toute impunité.

Le bilan de cette guerre menée par les colonnes républicaines constitue un troisième aspect de l'ouvrage. Anne Rolland-Boulestreau s'emploie ainsi à établir le décompte des victimes des colonnes et propose un total de 19174 Vendéens déclarés tués entre janvier 1794 et le printemps 1795. Le propos ne convainc pas toujours, cependant, car la base documentaire est étroite. L'auteur souligne qu'à peine plus de $15 \%$ des rapports donnent un tableau précis des pertes vendéennes. En outre, peut-on prendre pour argent comptant les chiffres donnés par les généraux quand ceux-ci rendent compte de leur action? Vimeux, qui a remplacé Turreau, estime à la fin de sa mission que, du point de vue militaire, l'armée de l'Ouest a perdu la guerre. La dévastation du pays insurgé ne permet pas de briser l'insurrection et plusieurs rapports s'alarment au contraire du cercle vicieux qui se met en place : le " fer et le feu " portés au cœur de la Vendée militaire renforcent les rangs des insurgés. D'ailleurs, dès le printemps 1794, on perçoit une inflexion de la politique menée en Vendée. En avril, la dénonciation des violences faites aux femmes vendéennes par le représentant du peuple Lequinio y a contribué et Turreau est désavoué en mai. Le pouvoir politique met bientôt à l'ordre du jour la pacification en distinguant les " brigands " du reste de la population.

Bien qu'elle s'en tienne aux comptes rendus des généraux, en multipliant les angles d'attaque qui s'inspirent de l'historiographie récente, Anne RollandBoulestreau renouvelle profondément notre connaissance des " colonnes infernales ". Son ouvrage, qui tient à distance les discours militants et livre une analyse dépassionnée mais souvent passionnante de ce conflit asymétrique, est donc une entreprise salutaire. 